\title{
CONTRATOS DE PRODUCCIÓN AGROINDUSTRIAL. PRINCIPALES CARACTERÍSTICAS Y REFLEXIONES EN TORNO A SU UTILIZACIÓN
}

ELOISA HARAVÍ RUIZ

UNIVERSIDAD NACIONAL DEL NORDESTE - UNNE insanos por los que no podían escuchar la música”. 


\title{
RESUMEN
}

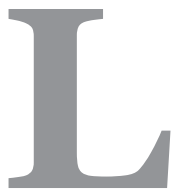

os contratos agroindustriales son una de las herramientas contractuales más utilizadas para instrumentar las actuales demandas del mercado de producción alimentaria. Diversos autores han caracterizado este contrato, clasificado sus cláusulas más usuales, e identificado sus funciones y finalidades de acuerdo a las prácticas contractuales y el análisis de legislación existente en países como Estados Unidos. Argentina, sin embargo, aún no cuenta con legislación específica. Este contrato crea un tipo de relación entre las partes que es única y diferente a los demás contratos agrarios tradicionalmente utilizados, buscando garantizarse la provisión de un producto agrario por un lado y garantizando la colocación de la producción por otro. Asimismo este acuerdo acentúa los procesos de integración de los diversos sectores productivos, que llevado a un extremo implica una pérdida casi absoluta del manejo de la propia empresa por parte del agricultor, corroborándose además la existencia frecuente de una marcada asimetría en perjuicio de los agricultores, remarcándose la necesidad de creación o aplicación de un régimen tuitivo especial. Así, algunos autores han ensayado la posibilidad de aplicación de la Ley del Consumidor ante la advertencia de un desequilibrio. Por otro lado, en el marco actual de creciente concentración económica, liberalización y retracción del aparato Estatal, el fenómeno de la contratación agroindustrial puede juzgarse preocupante para la pequeña empresa agraria, quien padece una dependencia y subordinación crítica hacia los empresarios elaboradores e industriales, surgiendo así el interrogante sobre el rol que el Estado desempeña en este tipo de relaciones contractuales y las concretas consecuencias de sus ausencias.

Palabras clave: pequeños productores - agricultura por contrato - agroindustria.

\begin{abstract}
Production Contracts are one of the most used contracts in order to respond the alimentary production's demand. Several authors have been described this contract, its clauses and functions according the real practices and the legislation from countries like United States. However, Argentina still doesn't have a specific production contract regulation. This contract creates a special relation between parties, which is quite different than most traditional agrarian contracts. It seeks to guarantee a specific production and a certain price. Also, this agreement increase integration process in the production chain, which in an extreme way would mean the loose of farm's independence. Furthermore, we can frequently find asymmetric bargaining power between parties which point out regulation's necessity. In this way some authors have tried the application of Consumer's Law. Finally, in the current political and economic scenery the production contracts phenomenon would be worrying for the small farmers, emerging some important questions like which is government role in this situation and which are the real consequences of its absence?
\end{abstract}

Keywords: small farmers - contract farming - agribusiness. 


\section{INTRODUCCIÓN: CONTEXTO Y FACTORES DE SU DESARROLLO}

Históricamente, el mecanismo de comercialización de los productos agrícolas fue la venta directa en los mercados al contado o abiertos ("spots marktes"), sin embargo esto se ha modificado progresivamente en el último siglo.

Estos cambios son imputados a una gran variedad de factores entre los cuales podemos nombrar el proceso de globalización, el progreso tecnológico (agrícola específicamente y comunicacional en general), el aumento de la demanda mundial de alimentos y la expansión de los derechos del consumidor así como al "refinamiento" de sus preferencias en cuanto a calidad y especificidad de los productos consumidos'.

Más allá de los factores que han originado estos cambios, lo que a nuestro análisis interesa es una de las herramientas contractuales más utilizadas para instrumentar las actuales demandas del mercado de producción alimentaria ${ }^{2}$.

Algunos autores han encarado el fenómeno de las nuevas modalidades de contratación de manera global, denominándolas "agricultura por contrato3", haciendo referencia a los acuerdos que se dan entre los agricultores y empresarios transformadores o comercializadores que tienen por objeto organizar la producción futura a precios generalmente determinados. Asimismo, éstas figuras contractuales disponen la prestación de servicios de asistencia técnica y suministro de insumos por parte de los empresarios con el objetivo de lograr un producto de determinada calidad (Eaton y Shepherd, 2001).

La descripción anterior establece una caracterización de las modalidades de contratación agroindustrial genérica, aplicable a un ámbito más extenso del que creemos pertenece estrictamente a los contratos de producción agroindustrial propiamente dichos.

Los mismos autores establecen seguidamente una clasificación de las modalidades o cláusulas contractuales, diferenciándolas según la "intensidad del arreglo contractual", es decir de acuerdo con la complejidad de las disposiciones contractuales que se prevean en el contrato, dividiéndolas en las siguientes:

- Disposiciones (cláusulas) sobre mercado: El agricultor y el comprador acuerdan los términos y condiciones para la compra y venta futura de un cultivo o producto agrario;

\footnotetext{
${ }^{1}$ Entre algunos de los autores que han descripto el fenómeno, podemos destacar: Ledesma, "El mayor poder adquisitivo de una parte de la población mundial impulsa nuevos hábitos de compra, muy ligados a la nutrición y la salud. Por ello se advierte una clara tendencia al consumo según criterios cualitativos más que cuantitativos" (Ledesma, 2007). En el mismo sentido Victoria "cada vez hay una mayor exigencia de calidad en todos los aspectos de la vida humana. El hombre moderno es cada vez más consciente de sus derechos y exige calidad en los productos que adquiere nada más y nada menos que para su alimentación” (Victoria, 2008)

${ }^{2}$ No es ilógico decir que en su mayoría, estos instrumentos contractuales son diseñados por las industrias, que son quienes obtienen los mayores beneficios.

${ }^{3}$ Eaton Charles y Shepherd Andrew W. (2001), Schejtman, Alejandro (1994), Minot Nicolás (1986), Hamilton Neil (1994, 1995), entre otros.
} 
- Disposiciones (cláusulas) sobre recursos: Junto con los arreglos sobre comercialización, el comprador acuerda suministrar insumos seleccionados, incluyendo, en ciertas ocasiones, la preparación de la tierra y la asistencia técnica;

- Definiciones (cláusulas) sobre administración: El agricultor acuerda aplicar los métodos de producción recomendados, los regímenes de insumos, y las especificaciones sobre procedimiento de cultivo y cosecha.

Podemos observar que el esquema clasificatorio propuesto diferencia tres tipos de cláusulas que pueden encontrarse en estos contratos. Según el criterio que sostenemos, un contrato agroindustrial propiamente dicho, sería aquel que reúne los tres tipos de cláusulas, es decir, aquel contrato que contiene disposiciones reglamentando los tres aspectos mencionados.

Observamos entonces, que desde aquellos contratos que solo disponen reglas básicas sobre el intercambio del producto por un precio (más asimilables al clásico contrato de compraventa) hasta aquellos que llegan a determinar mínimos detalles respecto del tracto de ejecución contractual, existe un considerable aumento de la cantidad de aspectos normados, así como una mayor "intervención reglamentaria" en la actividad productiva que debe llevar a cabo el agricultor.

\section{PAÍSES DONDE ADQUIRIÓ MAYOR DESARROLLO. CONCEPTOS}

Estos instrumentos negociales adquirieron un importante desarrollo en Estados Unidos, Francia, España e Italia, países que desde hace algunas décadas ya cuentan con legislación específica para regularlos.

En general, los esquemas contractuales utilizados en los países nombrados son similares (en cuanto a la prestación principal, partes intervinientes y modalidades), siendo las diferencias que contienen consecuencia de los distintos modos de legislarla y de los diversos sistemas e instituciones jurídicas. Con las anteriores salvedades, todos los contratos calificados generalmente por la doctrina como de producción, poseen recurrentes características.

Como primera aproximación, comentaremos algunas de las caracterizaciones de aquellos autores que han concentrado su trabajo en el estudio de esta figura.

En este sentido Neil D. Hamilton ${ }^{4}$ (1995), uno de los autores que ha estudiado exhaustivamente el tema en Estados Unidos ${ }^{5}$, la ha caracterizado como un acuerdo a plazo fijo legalmente vinculante, perfeccionado antes de que comience la producción, en el que un productor se compromete a vender o entregar un cultivo específico, producido en hectáreas identificadas y designadas contractualmente, y realizado de acuerdo a especificaciones técnicas esta-

\footnotetext{
${ }^{4}$ Director del Agricultural Law Center en Drake University Law School, Drake University Law School, Des Moines, Estados Unidos.

${ }^{5}$ Es oportuno aclarar que los Estados Agrícolas de aquella nación tienen regulado este Contrato desde hace varias décadas; normativa que es complementada por disposiciones reguladoras de la Competencia y Comercialización de nivel Federal.
} 
blecidas al contratista, por el cual recibe el pago de un precio (fijo o calculado de acuerdo a un procedimiento establecido en el contrato), o bien es aquel acuerdo donde se compromete a alimentar y cuidar del ganado o de aves de corral propiedad del contratista hasta el momento en que los animales son retirados, a cambio de un pago en función del rendimiento de los animales. Según el acuerdo, el productor puede no tener la titularidad legal [de la propiedad] de la cosecha o el ganado, siendo un depositario, declarándose además como contratista independiente y no un empleado o empresa vinculada con el contratista".

Expresa Hamilton que este contrato crea un tipo de relación entre las partes que es única y diferente a los demás contratos agrarios tradicionalmente utilizados. Para él, las distinciones más importantes con las herramientas contractuales clásicas, son que estas últimas no incluyen cláusulas que facultan al co-contratante a controlar el proceso productivo (es decir, la ejecución de la prestación a cargo del productor agrario), no contemplan la posibilidad de que lo producido sea propiedad del empresario procesador desde la siembra ${ }^{7}$, y que los contratos tradicionales requieren la "venta" y por ende la transferencia de la propiedad de lo producido al final del ciclo, que no necesariamente se lleva a cabo en los contratos agroindustriales, si no que solo se "entrega" la producción en atención a que el productor la mayoría de las veces nunca fue estrictamente "propietario" de lo sembrado y cosechado. La clave está en que en todas las formas o figuras "clásicas" de comercialización de los bienes producidos, la producción es propiedad del agricultor hasta la venta (Hamilton, 1995), cuestión que no ocurre, como vimos, en los contratos agroindustriales norteamericanos.

Esta característica no se encuentra presente en los contratos de producción agrícola de nuestro país, donde el agricultor sí es propietario de lo sembrado y cosechado, y donde sí existe una venta (y transferencia de propiedad) de lo producido al industrial al finalizar el mismo.

En cambio, es común la "retención de la propiedad" en cabeza del procesador industrial en el caso de los contratos de producción de cría animales (avícola, ganaderos, porcinos, etc.). Esto se debe principalmente a que en el contrato agroindustrial de siembra, el empresario vende las semillas al productor, existiendo por ende traspaso de propiedad a favor del agricultor, a diferencia de los contratos de cría o engorde de ganado donde solo se entrega la tenencia de las crías o animales para engorde al productor, no existiendo una venta en la mayoría de los casos.

Por otro lado, podemos citar a Christopher R. Kelley (1995) quien focalizando en otros aspectos de esta figura contractual, comenta al respecto que frecuentemente el contratante [empresario elaborador] es el que transforma el fruto agrario producido bajo este contrato

\footnotetext{
${ }^{6}$ La traducción me pertenece.

${ }^{7}$ Se sostiene que el empresario industrial o semillero titular de la propiedad de la semilla, mantiene dicha propiedad sobre el cultivo que nace de ellas, produciéndose una suerte de transformación o mutación del objeto cuya propiedad detenta, manteniendo en todo momento un acuerdo llamado en el derecho norteamericano Bailment Agreetment con el productor agrícola (figura inexistente en nuestro derecho, que consiste en la transferencia de la posesión de una cosa pero no su propiedad).
} 
en un producto de mayor valor agregado. Los contratos de producción permiten a este contratante controlar tanto la cantidad como la calidad de lo que ellos producen. Otros contratantes comercializan los frutos sin darles ningún valor agregado, pero usan los contratos de producción para preservar la identidad de sus productos y para controlar el acceso a su propiedad intelectual biotecnológica. Un grupo más pequeño pero significante de contratantes, son los mismos agricultores que utilizan los contratos de producción para completar una etapa el ciclo productivo que está más allá de sus propias habilidades y capacidades ${ }^{8}$.

Esta definición se concentra en describir algunos de los motivos de la utilización de esta figura y que quizás configuran algunas de las razones del vertiginoso crecimiento de su uso: el contrato de producción es un modo eficaz de asegurarse regularmente un insumo altamente específico en cuanto características organolépticas, así como es una herramienta de reproducción y control de "cultivos con identidad preservada".

En efecto, incluyendo cláusulas que regulen derechos de propiedad intelectual involucrados en el uso de ciertas variedades de semillas, se busca controlar y restringir el acceso a biotecnología, explotando las regalías de su uso en el mayor margen posible y restringiendo asimismo el manejo de las semillas por parte del productor ${ }^{10}$.

Por último, Kelley enumera en su caracterización otra posible finalidad: la de aquellos productores agrícolas que deciden la utilización del contrato para dar algún valor agregado o grado de elaboración a su producción antes de comercializarla. En este último supuesto, que encontramos más cercano a la maquila, el contrato no es de producción agrícola propiamente dicho, si no de elaboración o procesamiento. El objeto contractual deja de ser la siembra, producción y cosecha o cría para pasar a ser de elaboración de cierto producto derivado o mejorado (procesados, embasados, refinados, etc.).

En nuestro país la maquila es usada comúnmente para la elaboración de azúcar, vino y aceite. Este contrato fue receptado legalmente en nuestro país para la vitivinicultura por Ley 18.60o, y aplicado prácticamente con carácter de emergencia por Decreto del Poder Ejecutivo en 1985 para la comercialización de caña de azúcar. Posteriormente por Ley 25.113 de 1999 se receptó la figura, asignándole carácter general.

En ambos casos el agricultor mantiene la propiedad de la materia prima durante todo el proceso productivo, y pesa sobre el empresario elaborador las obligaciones de "hacer" consistentes en la elaboración y entrega en tiempo oportuno del producto.

\footnotetext{
${ }^{8}$ La traducción me pertenece.

${ }^{9}$ Protegidos por el derecho de propiedad intelectual.

${ }^{10}$ Este tema se relaciona con una de las cuestiones más debatidas en la actualidad respecto a los derechos de propiedad intelectual en el mundo agrario: los desarrollos biotecnológicos y la extensión de la protección legal a derechos de propiedad intelectual aplicados a cultivos y sus productos derivados, así como el conflicto que esto genera con derechos tradicionalmente reconocidos al productor (derechos del obtentor, etc.).
} 
Por lo que se puede observar de la breve descripción anterior, la maquila es un contrato que si bien tiene por objeto la "producción", lo es en el sentido de la elaboración o manufacturación de un producto derivado del fruto agrario, por lo que el objeto difiere de lo que aquí denominamos contrato agroindustrial propiamente dicho.

Por todo lo anterior, consideramos que el contrato de maquila sería más bien un antecedente de los contratos agroindustriales, ya que no contiene la mayoría de los caracteres complejos que describimos en este artículo.

De todos modos, es un tema que merece ser analizado con mayor atención, ya que este contrato se encuentra legislado en nuestro país mediante la ley 25.113, cuyo artículo 6 establece su aplicación obligatoria para "todos los contratos agroindustriales". Creemos que esta pretendida aplicación extensiva a "todos" los contratos agroindustriales no es adecuada ni posible en la actualidad, ya que dicha norma resulta totalmente inidónea para regularlos debido a su actual complejidad y diferencias, como acabamos de esbozar.

Asimismo, entre los autores argentinos, Casella (2001) al igual que Kelley, incluye como contratos agroindustriales a aquellos acuerdos que buscan garantizar al industrial y/o comerciante la provisión de determinado producto de cierta calidad y en el tiempo convenido, pero resaltando también que de este modo el productor agrario se garantiza la colocación de su producción a precios de referencia, pudiendo contar con el adelanto de insumos y/o de recursos financieros, y asistencia técnica. Asimismo Casella pone énfasis en que el presente acuerdo acentúa los procesos de integración de los diversos sectores productivos, llegando incluso a actuar el productor agrario en algunos casos como una mera empresa de servicios del procesador.

El destacado agrarista argentino remarca en su caracterización del contrato los procesos de integración de fases productivas implicados en la adopción de este tipo de figura legal, que llevado a un extremo implica una pérdida casi absoluta del manejo de la propia empresa por parte del agricultor, quien se convierte en un mero ejecutor de órdenes del empresario comercial, un prestador de servicios, pero manteniendo consigo todo el riesgo empresarial propio de la fase productiva.

Finalmente, luego de haber expuesto algunas importantes caracterizaciones de esta figura ${ }^{11}$ podemos aventurar un concepto: el contrato de producción agroindustrial es aquel por el cual una parte (industrial, procesador, acopiador o comerciante) conviene con un agricultor o ganadero, cierta producción agrícola o cría de animales en un lugar específico (parcela de campo o establecimiento agrícola) detallando su cantidad y calidad, a cambio de una contraprestación que generalmente es un precio en dinero (que puede ser fijo o determinable a través de sistemas preestablecidos contractualmente, incluyendo premios o castigos por los logros productivos), pero que también puede consistir en parte de lo producido. Asimismo, el industrial

\footnotetext{
${ }^{11}$ Dejamos sin embargo aclarado que hemos omitido la inclusión de definiciones dadas por famosos tratadistas como las dadas por el
} Dr. Brebbia Fernando P., por estrictas razones de brevedad, las cuales no son menos importantes que las expuestas en este artículo. 
provee los insumos más importantes al productor (la semilla y/o fertilizantes, el ganado para cría o engorde, etc.) en forma de adelanto y a cuenta de precio, y el cumplimiento del acuerdo frecuentemente es garantizado por el agricultor mediante algún título de crédito ejecutivo. El productor además está obligado contractualmente a respetar ciertas directivas técnicas de cría o manejo del cultivo, estableciéndose expresamente prerrogativas (facultades) de control del ciclo productivo a favor del empresario industrial.

\section{SUS RASGOS LEGALES TÍPICOS}

Avanzando en el análisis que proponemos, intentaremos puntualizar los rasgos sobresalientes y distintivos de esta figura, recurriendo para ello a conceptos y clasificaciones provenientes de la Teoría General de los Contratos.

Para comenzar, debemos resaltar que este contrato se perfecciona entre dos sujetos claramente definidos. Los contratantes son, por un lado un agricultor o empresario agrario ${ }^{12}, \mathrm{y}$ por otro lado un empresario ${ }^{13}$ procesador o industrial, o una empresa titular de derechos sobre semillas genéticamente modificadas protegidas legalmente con patentes ${ }^{14}$.

En segundo lugar, sostenemos junto con la mayoría de la doctrina, que el contrato en estudio es un contrato de carácter bilateral, oneroso y de tracto sucesivo. De modo que, como consecuencia de la existencia de obligaciones recíprocas que deben ser cumplidas en diferentes momentos temporales, surgen una serie de consecuencias legales.

Siguiendo a Lorenzetti (2004) y Gregorini Clusellas (2009) en este punto, enumeraremos brevemente algunas de las más importantes que consideramos aplicables al contrato analizado, sin por ello descartar la existencia de otras.

- Opera la obligación del doble ejemplar (art. 1021 Cód. Civ.)

- Una de las partes no incurre en mora si la otra no cumple o no se allana a cumplir la obligación que le es respectiva (art. 510 del Cód. Civ.)

- Existiendo obligaciones recíprocas, una de las partes no puede demandar el cumpli-

\footnotetext{
${ }^{12}$ No se profundizara en estos conceptos por exceder el propósito del artículo. Sin embargo se recomienda la lectura de la conocida obra "Derecho Agrario" (Brebbia Fernando P. y Malanos Nancy, 1997, p. 182-186) en donde el famoso Agrarista realiza algunas precisiones terminológicas respecto al concepto de Empresario Agrario.

${ }^{13}$ En igual sentido que lo aclarado en la nota anterior, podrá consultarse obras de Derecho Comercial como las escritas por el Doctor Garrone José A., titulada “Derecho Comercial” (2004, p. 125-131).

${ }^{14}$ Existen en la actualidad en el ámbito internacional y nacional dos sistemas protección de la propiedad industrial para las nuevas biotecnologías referidas a la materia viva: el Sistema de Patentes y el Sistema de Derecho del Obtentor. Nuestro país protege estas diferentes innovaciones a través del derecho de patentes establecido en la Ley de Patentes de Invención y Modelos de Utilidad N²4.481 y su Decreto Reglamentario N²60/96, cuya autoridad de aplicación es el Instituto Nacional de la Propiedad Industrial (INPI) y por el sistema de derecho de obtentor establecido por la Ley $N^{\circ} 20.247$ de Semillas y Creaciones Fitogenéticas para las variedades vegetales, su Decreto Reglamentario N²183/91 y el Decreto 2817/91 cuya autoridad de aplicación es el Instituto Nacional de Semillas (INASE).
} 
miento si no prueba que ella cumplió u ofreciese cumplir (1021 Cód. Civ.). Una de las partes tiene derecho a suspender el propio cumplimiento hasta que la otra cumpla la prestación a su cargo, siempre que haya un plazo vencido.

- Suspensión del propio cumplimiento: en la compraventa (y creemos que analógicamente es aplicable) el deudor de entregar la cosa, puede no hacerlo si el comprador está en insolvencia (art. 1419 Cód. Civ.).

- Resolución: aquí se aplica el pacto comisorio (arts. 1203 y 1204 Cód. Civ. y 204 del Cód. Com.).

- Imposibilidad de pago: cuando la prestación se vuelve física o legalmente imposible sin culpa del deudor (art. 888 Cód. Civ.). El efecto en estos casos es la restitución recíproca de lo entregado (art. 895, Cód. Civ.). Sin embargo muchas veces esto no será posible en atención al objeto específico del contrato. No se concibe por ejemplo, que el productor pueda devolver las semillas plantadas, o el pesticida o fertilizante utilizado.

Habrá que ver en cada caso concreto, si es justo y lícito el cobro íntegro de dichos insumos adelantados, o si por el contrario la imposibilidad sobreviniente de cumplimiento es un riesgo que debe ser soportado por ambos contratantes.

- Existencia de Lesión: solamente aplicable a los actos jurídicos bilaterales y onerosos, y en caso de verificarse lo exigido por la norma.

- Aplicación de la Teoría de la Imprevisión. Revisión del Contrato (art. 1198 Cod. Civ.): sabemos que, según esta teoría receptada legalmente con la última gran reforma al Código Civil, si alguna de las prestaciones a cargo de las partes se tornara excesivamente onerosa por un hecho posterior, imprevisible y extraordinario, si no hubiere culpa ni mora de su parte, ésta podrá pedir resolución del contrato, mientras que la otra podrá pedir un reajuste para evitar la resolución del mismo. Sin embargo, debido a la cuantía y la naturaleza de las prestaciones en juego, creemos que el afectado por la excesiva onerosidad podrá pedir reajuste de su prestación ab initio y no solo la resolución.

Tercero, como expresamos anteriormente, nos encontramos frente a un contrato de tracto sucesivo. Con respecto a esta característica, conviene destacar que la mayoría de las obligaciones en el contrato en estudio son cronológicamente correlativas. Es decir, cada obligación (que como vimos no es una, si no varias) tiene cronológicamente un momento diferente y específico de cumplimiento. A modo de ejemplo, la obligación de suministrar los insumos tiene una época de cumplimiento que es anterior a las obligaciones (o facultad) de control, de recepción de la cosecha, y de pago. La obligación de suministrar las semillas es anterior a la de suministrar los pesticidas, pero esta última a su vez es temporalmente anterior a la de recibir la cosecha.

En consecuencia, el cumplimiento tardío o deficiente de alguna de estas prestaciones podría alterar negativamente la cadena de ejecución de prestaciones, produciendo perjuicios irreparables al cumplimiento de las prestaciones de la otra parte. Por ejemplo, la entrega tardía de las semillas para siembra, puede repercutir luego en la calidad o cantidad de producción lograda; también pueden provocar tal daño la falta de entrega o entrega deficiente (por 
ejemplo, menos cantidad de la necesaria) de pesticida, fertilizantes, o vacunas en el caso del contrato de cría o engorde de animales. No debemos olvidarnos además que estamos frente a un contrato que tiene como objeto la producción agraria, la cual cumple un ciclo biológico prácticamente inalterable, por lo que los plazos de cumplimiento de las diferentes prestaciones se tornan aun más estrictos y fatales que en otros contratos.

En otro orden de ideas, consideramos de suma importancia determinar cuál es el objeto del contrato en estudio. ¿El productor se obliga principalmente a la producción de determinado fruto o a la entrega (venta) en determinada fecha de ese fruto? El estudio de esta cuestión nos lleva a determinar si nos encontramos en presencia de un contrato más cercano a la locación de obra (si optamos por concentrarnos en la actividad productiva del fruto o el proceso de cría o engorde) o de una compraventa - de cosa futura si se quiere- (si decidimos que lo central en el contrato es la venta o entrega de ese fruto producido, al final del proceso productivo).

Esta diferencia no es solo teórica, ya que la aplicación o asimilación a uno u otro régimen, trae consecuencias diversas en la regulación aplicable.

A nuestro criterio, esta definición va a depender de que el objeto se trate de la cría o engorde animales, o de un contrato cuyo objeto es la producción de determinada cosecha. Efectivamente, en el caso de animales para engorde, creemos que se trata de Contrato de Locación y no de una Compraventa, ya que el ganado nunca es propiedad del agricultor que se encarga del engorde, si no que éste se limita a prestar una obligación de hacer (servicio de cría o engorde) al dueño del ganado, siendo por ello la figura contractual en análisis más cercana a las locaciones (de servicio o de obra) que a una compraventa.

Resulta más complicada la determinación de la naturaleza del contrato cuando tiene por objeto la siembra y cosecha agrícola, ya que en este caso sí existe propiedad del agricultor sobre lo sembrado y cosechado hasta el momento de la entrega al empresario industrial o comercial al finalizar el contrato.

Creemos que aquí nos encontramos con una figura más cercana al contrato de compraventa de cosecha futura, ya que existe traspaso de propiedad a cambio de un precio, y se perfecciona sobre un objeto que todavía no existe ${ }^{15}$.

Sin embargo, dada la naturaleza compleja de la presente figura, observamos que sus caracteres exceden ampliamente la simple compraventa futura. La existencia de múltiples obligaciones correlativas vinculadas al objeto principal, pero a la vez con cierta autonomía (caso del adelanto de insumos a cuenta de precio, o de la emisión de garantías por parte del productor) nos sugiere la importancia que tiene en la figura en examen el tracto de ejecución contractual, es decir, el desenvolvimiento del proceso productivo.

${ }^{15}$ Sobre la semilla opera un proceso de transformación. Cabe discernir si la semilla es el trigo (en un estado de evolución posterior) u opera una transformación, siendo ambos entidades diferentes. 
Por último, queremos remarcar la existencia de un complejo de prestaciones, ya que como expresa Confortini y Zimatore "el contrato agroindustrial supone una relación en la que se combina "una densa trama de obligaciones recíprocas", las que, además del efecto traslativo de la propiedad sobre los productos objeto del contrato, hace nacer múltiples obligaciones de hacer" (Confortini y Zimatore en Brebbia y Malanos, 2002).

Es así que se puede identificar una prestación principal declarada como objeto del contrato (la producción a cambio de un precio) y una variada gama de prestaciones consistentes en obligaciones de hacer, no hacer y de dar que pueden ser llamadas secundarias.

En efecto, si consideramos estas últimas en relación a la principal, claramente vemos su carácter de "satélites", ya que ayudan al cumplimiento de la obligación central. Sin embargo, si analizamos individualmente el contenido de estas prestaciones accesorias, observaremos que configuran una suerte de pequeños contratos anexados al principal. A modo de ejemplo, la provisión de insumos inicial se realiza generalmente a cuenta de precio, es decir, se difiere su pago al momento de la entrega de la producción, momento en el que serán descontados del precio a recibir por el productor agrario, quedando lisa y llanamente configurado un contrato de compraventa financiada, por lo que será aplicable a nuestro criterio, por ejemplo, la garantía por vicios redhibitorios.

También sostenemos que configura un contrato accesorio vinculado al principal el frecuente libramiento de títulos de crédito ejecutivos a fin de garantizar la operación (el cumplimiento del contrato). Por ello, teniendo en cuenta las consecuencias legales que trae aparejado un título ejecutivo (abstracción de la causa que le dio origen, independencia, etc.) es recomendable que al menos sean vinculados al negocio en virtud del cual se emiten. En realidad, considerando la ejecutividad que estos instrumentos traen aparejados, no es recomendable su utilización para garantizar contratos como el que estudiamos, ya que si por algún motivo el contrato principal no puede cumplirse por causas ajenas al productor o extraordinarias a ambas, estos títulos serían de cualquier modo ejecutables, dejándolo expuesto a tener que afrontar pagos injustificados o abusivos.

En este sentido, podría ser de utilidad la teoría de la conexidad contractual ${ }^{16}$, ya que muchas veces estos títulos, o la toma de empréstitos personales garantizados a través de fianzas, prendas o hipotecas, son motivados en la necesidad de cumplimentar requisitos exigidos por las empresas comerciales o elaboradoras para perfeccionar el contrato. Este esquema comentado se ha visto con mucha frecuencia en el sector avícola.

${ }^{16}$ Recomendamos en este punto el extenso análisis que hacen prestigiosos autores de la doctrina nacional en la Revista de Derecho Privado y Comunitario de Editoral Rubinzal Culzoni, 2007-2, titulada "Contratos Conexos". 


\section{REFLEXIONES EN TORNO A LOS CONTRATOS AGROINDUSTRIALES, SUS FUNCIONES EN EL SISTEMA PRODUCTIVO}

Finalmente, pasando a la segunda parte de este artículo, trataremos brevemente de dejar planteada algunas reflexiones referentes a este contrato, sus funciones en el sistema productivo actual y su uso. Aspectos que, desde nuestro punto de vista, deben ser estudiados con mayor profundidad en aras de una cabal comprensión de la figura contractual y su rol e implicancias en la actualidad.

\subsection{EL USO CRECIENTE DE CONTRATOS DE ADHESIÓN EN LAS CONTRATACIONES AGROINDUSTRIALES Y LA PROLIFERACIÓN DE CONTRATOS CON CLÁUSULAS ABUSIVAS}

La doctrina nacional e internacional especialista en el tema ha dicho que la ausencia de control estatal y de configuración legal como en el caso Argentino, produce como resultado en el plano de la realidad un terreno propicio para la aparición y proliferación de contratos y prácticas abusivas, cuando las partes contratantes poseen desiguales poderes negociales. En otras palabras, cuando algún tipo de situación de vulnerabilidad ${ }^{17}$ afecta a alguno de los contratantes.

En el caso en estudio, se corrobora la frecuente existencia de una marcada asimetría en perjuicio de los productores agrarios, basada fundamentalmente en la gran dispersión de la oferta por razones de lejanía geográfica de las producciones y una reducida capacidad negociadora del sector, entre otros motivos (Formento y Pilatti, 2004). A esto agregaríamos la existencia no poco frecuente de debilidad o vulnerabilidad estructural del sector.

Algunos autores señalan que la ley 24.240 (Ley del Consumidor) debería prever la aplicabilidad de su normativa también a aquellos contratos en los que, aún cuando la parte "débil" no sea consumidor final, las circunstancias permitan advertir un evidente desequilibrio o falta de equidad en el contenido de la contratación, como consecuencia de la posición dominante en el mercado de una de las partes ${ }^{18}$.

Sabemos que el empresario ha sido tradicionalmente excluido de la noción de consumidor porque los bienes por éste adquiridos normalmente son utilizados a su vez para procesos productivos $^{19}$. Surge así el problema que plantea el caso del pequeño empresario que contrata con grandes proveedores, por ejemplo para la compra de tecnología.

\footnotetext{
${ }^{17}$ Con respecto al desarrollo del concepto y clases de vulnerabilidad, se recomienda la lectura de LORENZETTI, Ricardo Luis, "Consumidores" Segunda Ed. Actualizada. Rubinzal Culzoni Ed. 2009. Sta. Fe. Págs. 35 a 40.

${ }^{18}$ Algunos autores han hablado de abusos de posición dominante en las contrataciones agrarias (SARAVIA, Luis Adolfo, "Abusos contra Productores: abuso de posición dominante en las actividades agropecuarias", Ed. Milor, Salta 2007).

${ }^{19}$ En este sentido: Resolución Mercosur GMC 123/96.
} 
Creemos que no existen diferencias sustanciales con lo que le acontece al consumidor en muchas ocasiones al comprar un producto tecnológico, en cuanto a la existencia de grandes asimetrías en la información.

En este último sentido, se señala que el concepto de consumidor ha tendido recientemente a su ampliación, principalmente en razón de ciertas situaciones en las cuales el adquirente se encuentra en condiciones de debilidad asimilables a las que padece el consumidor, pero sin calificar dentro de la categoría, como es el caso de los pequeños comerciantes, profesiones liberales, etc. (Mosset Iturraspe y Wajntraub, 2008).

La aplicación de la ley del consumidor en estos casos es un tema arduamente discutido, más aún cuando se trata de pequeñas empresas y microempresas ${ }^{20}$. Sin embargo actualmente en Argentina, la doctrina mayoritaria niega la aplicación de este régimen tuitivo a este tipo de relaciones, en razón del destino final del bien objeto de la contratación ${ }^{21}$.

\subsection{LA RELACIÓN EXISTENTE ENTRE LA AUSENCIA DE POLÍTICAS PÚBLICAS ESTATALES ESPECÍFICAS PARA EL SECTOR Y EL AUMENTO DE CONTRATOS ABUSIVOS}

Como habíamos comentado en la introducción del presente artículo, mientras la agricultura por contrato se remonta al Siglo XIX en los Estados Unidos y al menos a la década de 1940 en América Latina, en los últimos años estas prácticas contractuales han experimentado una expansión considerable en todo el mundo, llamando la atención de los partidarios y detractores del fenómeno (Warning y Soo Hoo, 2000).

Desde un punto de vista, se sostiene que este tipo de contrato ha sustituido y reemplazado la ausencia y retracción del Estado en el sector como proveedor de insumos subsidiados, de servicios de extensión técnicos, de crédito "barato", etc. En este sentido se sostiene que las empresas privadas pueden desempeñar los mismos roles y de manera más eficiente. En cambio, otro sector doctrinario considera a estos contratos como instrumentos a través de los cuales las empresas agroindustriales pueden imponer relaciones desiguales de poder con los productores, en particular con los pequeños (Warning et al, 2000).

Desde este último punto de vista, en el marco actual de creciente concentración económica, de liberalización y retracción del aparato Estatal, el complejo fenómeno de la contratación

\footnotetext{
${ }_{20}$ La doctrina Francesa ha decidido a favor de la aplicación del estatuto a casos entre empresarios, cuando se observa la no especialidad de uno de ellos respecto del objeto del contrato (Lima Márquez, 2005).

${ }^{21}$ En este sentido, resulta interesante destacar, a modo ejemplificativo, la ley 20.16 de Chile, que, buscando equilibrar las relaciones entre los proveedores de bienes y servicios y las micro y pequeñas empresas sanciona esta ley con el objetivo de que este tipo de relaciones comerciales se desarrollen bajo el mismo concepto de protección al consumidor, que hoy consagra la legislación nacional chilena. De esta manera, se transforma a la Mype (MicroPyme) en un sujeto activo de derechos y acciones consagrados en la Ley de Protección al Consumidor, respecto de las relaciones con sus proveedores.
} 
agroindustrial puede juzgarse por lo menos preocupante para la pequeña empresa familiar agraria o los pequeños productores, quienes padecen una dependencia y subordinación crítica hacia las empresas agroproductoras neurálgicas, si no se cuenta con la legislación, los instrumentos y los criterios interpretativos adecuados, es decir con el acompañamiento de un Estado que dé respuestas adecuadas y eficientes a las necesidades del sector (Casella, 2001).

Es así que en el contexto antes descripto, surge la preocupación sobre el papel que el Estado desempeña en este tipo de relaciones contractuales y las concretas consecuencias de sus omisiones, ausencias y falta de respuesta a las demandas del sector, así como el verdadero impacto de la promulgación de normas específicas, programas y actividades de asistencia al sector.

Es así que surgen interrogantes acerca de la existencia de alguna relación entre la mayor desregulación sobre la actividad agrícola como política de Estado y la proliferación de estas complejas relaciones contractuales. Asimismo, también nos preguntamos si existe alguna relación entre la proliferación de contratos altamente desiguales y subordinantes y la ausencia de regulación específica del Estado.

La importancia de una investigación que aporte a la aclaración de estos interrogantes sin dudas dejará en evidencia el impacto de la falta de políticas públicas en la "calidad" de contratos agroindustriales a la cual se someten los pequeños productores, contribuyendo a esclarecer el rol actual del Estado en tales prácticas, de primordial importancia para el diseño de programas y políticas de asistencia.

En este sentido, adelantamos que consideramos que la ausencia de Políticas Públicas específicas del Estado hacia el sector ha facilitado la aparición de prácticas abusivas y lesivas en las relaciones contractuales agroindustriales, principalmente aquellas que se concretan entre los pequeños productores y las empresas procesadoras.

\section{CONCLUSIONES}

Finalmente y a manera de conclusión, podemos observar que la figura, a pesar de no contar con legislación específica alguna, contiene rasgos bastante definidos. En efecto, el contrato de producción agroindustrial es un contrato de naturaleza compleja que puede tener principalmente dos clases de objetos, ambos vinculados a la producción vegetal o animal. Asimismo, es un contrato de vincula a actores de la cadena productiva específicos, siendo siempre uno de ellos del sector de la producción agraria ${ }^{22}$.

Otro importante rasgo típico lo configura la multiplicidad y diversidad de prestaciones a cargo de cada una de las partes, en donde puede identificarse una principal, consistente en la producción y entrega de un producto agrícola o animal a cambio de un precio, prestación que se encuentra rodeada de obligaciones accesorias a esta principal.

${ }^{22}$ Por lo que sostenemos enfáticamente su calidad de contrato agrario. 
En este punto, conviene volver a enfatizar en que el objeto del contrato estudiado involucra un ciclo biológico (crecimiento vegetal o animal) que puede adicionar notas peculiares al desarrollo del tracto ejecutivo del contrato que conviene no dejar de lado.

Asimismo, la cercanía de este contrato con figuras legisladas como la locación de obra o la compraventa dependerá en gran medida de que el objeto contractual sean animales o vegetales. No obstante, en ningún caso es posible una asimilación absoluta a ninguna de las figuras legisladas.

Conviene tener en cuenta el aumento en el uso de contratos de adhesión, en donde el predisponente generalmente es el empresario comercial o procesador. El uso de esta modalidad, sumada a la existencia de sectores de agricultores altamente vulnerables concentrados en algunas zonas de nuestro país, nos lleva a reflexionar acerca de la necesidad de dar una solución a las eventuales prácticas abusivas mediante la sanción de una norma regulatoria específica, o mediante aplicaciones analógicas de cuerpos normativos protectorios actualmente vigentes, como lo es la nombrada Ley del Consumidor. Sin embargo, la mentada aplicación "analógica" de esta ley a situaciones asimétricas similares a la de los consumidores, no es aceptada actualmente por la doctrina mayoritaria de nuestro país, en tanto tales situaciones no configuran relaciones de consumo propiamente dichas.

Por último, conviene profundizar el estudio de las causas del aumento vertiginoso del uso de esta figura, así como de la existencia de prácticas abusivas en el tracto ejecutivo contractual. En este sentido consideramos que el Estado no solo ha coadyuvado - mediante inacción y ausencia - al crecimiento en su utilización, si no que, mediante la retracción estatal y la falta de políticas claras para el sector, se ha contribuido indirectamente al aumento de prácticas altamente cuestionables. En efecto, el contrato de producción agroindustrial - mal o bien - ha venido a llenar un vacío de presencia del Estado, en cuanto proveedor de crédito, de asistencia técnica, de promotor de la producción agrícola, entre otras funciones importantes que el Estado puede asumir en apoyo al sector.

\section{REFERENCIAS BIBLIOGRÁFICAS}

Brebbia F. y Malanos N. (2002). Tratado Teórico Practico de los Contratos Agrarios. Buenos Aires: Rubinzal Culzoni, p.364.

Casella A. P. (2001). Modalidades negociales de la empresa agraria en el marco del Complejo agroindustrial y agroalimentario. Comunicaciones Científicas y Tecnológicas de la Facultad de Derecho, Ciencias Sociales y Políticas, Universidad Nacional del Nordeste. Corrientes, pp.2- 3.

Eaton C. y Shepherd A. W. (2001). La agricultura por Contrato. Alianzas para el crecimiento. Boletín de Servicios Agrícolas de la FAO No 145 . Organización de las Naciones Unidas para la Agricultura y la Alimentación. Roma. Recuperado de: www.fao.org/docrep/004/ y0937s/yo937soo.htm, pp. 11-12 
Formento S. y Pilatti H. H. (2004). Los Contratos Agroindustriales: su perfil jurídico. VII Congreso de derecho Argentino Agrario, Octubre 2004. Bahía Blanca. Recuperado de: www.iada.org.ar/eventos/anteriores/7congresoarg-2004/index.htm, p.11.

Gregorini Clusellas E. L. (2009). Derecho de los Contratos. Tomo 1. Buenos Aires: Hammurabi, pp. 260-279.

Hamilton N. D. (1995). Farmer's Legal Guide to Production Contracts. Research Proyect. The National Agricultural Center. University of Arkansas. School of Law-Division of Agriculture. Arkansas. Recuperado de: http://www.nationalaglawcenter.org/assets/articles/hamilton_ productioncontracts.pdf, p. 2.

Kelley C. R. (1995). Agricultural production contracts: drafting considerations. The Hamline Law Review. Spring, 1995, Hamline University-Law School. Saint-Paul-MN, p.2.

Ledesma, M.A., (2007). Agronegocios, Empresas y Emprendimientos. Buenos Aires: El Ateneo, p. 150.

Lima Márquez, C. (2005). Contratos No Código de Defensa do Consumidor. Ed. Revista Dos Tribunais, 5ta. Ed. San Pablo, p. 307.

Lorenzetti R. L. (2004). Tratado de los Contratos. Parte General. Buenos Aires: Rubinzal Culzoni Editores, pp. 211-212.

Mosset Iturraspe J. y Wajntraub J. H. (2008). Ley de Defensa del Consumidor. Santa Fe: Rubinzal Culzoni, p. 41.

Victoria, M. A. (2008). De la Seguridad Alimentaria a los derechos de los consumidores. Serie Difusión Científico - Técnicas Año 7- ${ }^{\circ} 7$, Facultad de Humanidades Ciencias Sociales y de la Salud. Santiago del Estero: Publicaciones del CeiDAACC, p. 35.

Warning M. y Soo Hoo W. (2000). The Impact of Contract Farming on Income Distribution: Theory and Evidence. Western Economics Association International Annual Meetings, June 30. Recuperado de: http://www2.ups.edu/econ/working_papers/oo-6.pdf, pp. 2- 3. 


\section{CURRÍCULUM VITAE}

HARAVÍ ELOISA RUIZ

Abogada, Becaria de Investigación de Perfeccionamiento Tipo B de la Universidad Nacional del Nordeste (UNNE), Docente Auxiliar de Primera en Instituciones de Derecho Privado II en la Facultad de Ciencias Económicas (UNNE), Adscripta de Derecho Comercial Primer Curso y de Derecho Agrario, de Minería, de la Energía y Ambiental en la Facultad de Derecho, Ciencias Sociales y Políticas (UNNE), Especialista en Docencia Universitaria y en Teoría y Práctica del Proceso Judicial. Doctoranda en el Doctorado en Ciencias Jurídicas de la Facultad de Derecho, Ciencias Sociales y Políticas de la Universidad Nacional del Nordeste.

haraviruiz@gmail.com 